University of South Florida

DIGITAL COMMONS

Digital Commons @ University of

@ UNIVERSITY OF SOUTH FLORIDA

South Florida

\title{
Pain as a motivator of smoking: Effects of pain induction on smoking urge and behavior
}

Joseph W. Ditre

University of South Florida

Follow this and additional works at: https://digitalcommons.usf.edu/etd

Part of the American Studies Commons

\section{Scholar Commons Citation}

Ditre, Joseph W., "Pain as a motivator of smoking: Effects of pain induction on smoking urge and behavior" (2006). USF Tampa Graduate Theses and Dissertations.

https://digitalcommons.usf.edu/etd/2503

This Thesis is brought to you for free and open access by the USF Graduate Theses and Dissertations at Digital Commons @ University of South Florida. It has been accepted for inclusion in USF Tampa Graduate Theses and Dissertations by an authorized administrator of Digital Commons @ University of South Florida. For more information, please contact digitalcommons@usf.edu. 
Pain as a Motivator of Smoking:

Effects of Pain Induction on Smoking Urge and Behavior

by

Joseph W. Ditre

A thesis submitted in partial fulfillment of the requirements for the degree of Master of Arts

Department of Psychology

College of Arts \& Sciences

University of South Florida

Major Professor: Thomas H. Brandon, Ph.D.

Paul B. Jacobsen, Ph.D.

Cynthia D. Myers, Ph.D.

Jamie L. Goldenberg, Ph.D.

Date of Approval:

November 20, 2006

Keywords: Tobacco; craving; cigarettes; cue-reactivity; cold-pressor

(C) Copyright 2007, Joseph W. Ditre 
Table of Contents

List of Tables $\quad$ ii

List of Figures iii

Abstract $\quad$ iv

Introduction 1

Method 6

Participants $\quad 6$

Design $\quad 7$

Manipulations $\quad 9$

$\begin{array}{lr}\text { Procedure } & 10\end{array}$

Results 14

Baseline Measures $\quad 14$

Manipulation Checks: Pain Intensity and Negative Affect 14

$\begin{array}{ll}\text { Primary Analyses } & 14\end{array}$

$\begin{array}{lr}\text { Additional Analyses } & 16\end{array}$

$\begin{array}{ll}\text { Discussion } & 21\end{array}$

$\begin{array}{ll}\text { References } & 26\end{array}$

Appendices $\quad 36$

Appendix A: Smoking Status Questionnaire $\quad 37$

Appendix B: Questionnaire of Smoking Urges-Brief 38

Appendix C: Visual Analogue Scale (VAS) 39

Appendix D: Smoking Consequences Questionnaire - Adult 40

Appendix E: PANAS-W 41

Appendix F: PANAS-I $\quad 42$

Appendix G: Pain Catastrophizing Scale $\quad 43$

Appendix H: NRS Measure of Pain Intensity 44 


\section{List of Tables}

Table 1 Marginal Means (and Standard Errors) for Post-Test

Measures of Smoking Motivation 


\section{List of Figures}

Figure 1 Conceptualization of the proposed reciprocal relationship between pain and smoking 


\author{
Pain as a Motivator of Smoking: \\ Effects of Pain Induction on Smoking Urge and Behavior \\ Joseph W. Ditre
}

\begin{abstract}
Tobacco smoking has been associated with the development, protraction, and exacerbation of chronically painful conditions. Conversely, there is reason to believe that smokers may be motivated to use tobacco as a means of coping with their pain. To date, no controlled, experimental studies have tested for a causal relationship between pain and smoking motivation. The primary aim of the current study was to test the hypothesis that laboratory-induced cold-pressor pain would enhance smoking motivation, as measured by self-reported urge to smoke and observation of immediate smoking behavior. The effect of a smoking cue was also tested. Smokers $(N=132)$ were randomly assigned to one of four conditions in this 2 (Pain Manipulation) $\times 2$ (Smoking Cue Manipulation) crossed factorial between-subjects design. Results indicated that both pain induction and the presence of smoking cues increased urge ratings, and pain induction also produced a shorter latency to smoke. The relationship between pain and increased urge to smoke was partially mediated by pain-induced negative affect. This study provides the first experimental evidence that situational pain can be a potent motivator of smoking.
\end{abstract}


Introduction

Despite evidence that smoking harms nearly every organ of the body, causing premature morbidity and mortality (USDHHS, 2004), approximately 50 million adults continue to smoke tobacco (CDC, 2005). According to the American Pain Society (2003), over 75 million Americans are totally or partially disabled by serious pain, and more than 50 million suffer from chronic nonmalignant pain. Pain and smoking have been linked in both the clinical and empirical literature for decades. In fact, the prevalence of smoking among individuals in pain is approximately double that of the general population, indicating that more than half of chronic pain patients are smokers (Brage \& Bjerkedal, 1996; Hagg, Fritzell, \& Nordwall, 2002; Jamison, Stetson, \& Parris, 1991; Nuprin, 1985). The empirical literature regarding the relationship between pain and smoking can be conceptualized as investigating either the effects of smoking on pain (e.g., smoking causing, increasing, or inhibiting pain) or the effects of pain on smoking (e.g., pain increasing smoking motivation), with the latter direction receiving far less attention.

Although a causal effect has yet to be demonstrated, a copious number of mostly cross-sectional studies provide evidence of an association between smoking and increased prevalence and aggravation of several painful conditions, including: musculoskeletal pain (Andersson, Ejlertsson, \& Leden, 1998; Biering-Sorensen \& Thomsen, 1986; Brage \& Bjerkedal, 1996; Eriksen, Brage, \& Bruusgaard, 1997; Frymoyer et al., 1980; Leino-Arjas, 1998; Lindal \& Stefansson, 1996; Palmer, Syddall, Cooper, \& Coggon, 2003; Scott, Goldberg, Mayo, Stock, \& Poitras, 1999), rheumatoid 
arthritis (Albano, Santana-Sahagun, \& Weisman, 2001; Harrison \& Silman, 2000; Hutchinson, Shepstone, Moots, Lear, \& Lynch, 2001; Krishnan, Sokka, \& Hannonen, 2003; Tuomi, Heliovaara, Palosuo, \& Aho, 1990), fibromyalgia (Wolfe \& Hawley, 1998; Yunus, Arslan, \& Aldag, 2002), oral pain (AI-Wahadni \& Linden, 2002; Johnson \& Slach, 2001; Kinane \& Chestnutt, 2000; Rees \& Addy, 2002; Riley, Tomar, \& Gilbert, 2004; Unell, Soderfeldt, Halling, \& Birkhed, 1999; Winn, 2001), cluster headaches (Beck, Sieber, \& Trejo, 2005; Ghandour, Overpeck, Huang, Kogan, \& Scheidt, 2004; Payne, Stetson et al., 1991; Rozen, 2005; Torelli, Cologno, \& Manzoni, 1999), and bodily pain in persons with HIV infection (Patel et al., 2006; Turner et al., 2001). Research also suggests that smoking is associated with an increased use of opioids by post-surgical patients in pain (Creekmore, Lugo, \& Weiland, 2004; Glasson, Sawyer, Lindley, \& Ginsberg, 2002; John et al., 2006; Woodside, 2000).

Conversely, several controlled experimental pain induction studies have found immediate analgesic effects of smoking. A direct pain-inhibitory effect of nicotine has been consistently demonstrated in animal studies (Aceto, Bagley, Dewey, Fu, \& Martin, 1986; Cooley et al., 1990; Mousa, Aloyo, \& Van Loon, 1988; Sahley \& Berntson, 1979). However, of 15 studies examining the influence of smoking on human pain perception, nine $(60 \%)$ reported a pain-inhibitory effect of smoking (Fertig, Pomerleau, \& Sanders, 1986; Girdler et al., 2005; Jamner, Girdler, Shapiro, \& Jarvik, 1998; Kanarek \& Carrington, 2004; Lane, Lefebvre, Rose, \& Keefe, 1995; Nesbitt, 1973; Pauli, Rau, Zhuang, Brody, \& Birbaumer, 1993; Pomerleau, Turk, \& Fertig, 1984; Silverstein, 1982), and six failed to observe smoking-related antinociception (Jarvik, Caskey, Rose, Herskovic, \& Sadeghpour, 1989; Knott, 1990; Shiffman \& Jarvik, 1984; Sult \& Moss, 1986; Unrod, Kassel, \& Robinson, 2004; Waller, Schalling, Levander, \& Edman, 1983). The mixed evidence for smoking-related analgesia in humans may stem from gender 
differences, the stimuli used to induce experimental pain, smoking history, and the possibility that the antinociceptive effects of smoking may be achieved indirectly via its action on other mediating psychological or physiological factors (Girdler et al., 2005; Jamner et al., 1998; Kanarek \& Carrington, 2004; Pomerleau et al., 1984; Shiffman \& Jarvik, 1984; Unrod et al., 2004).

Tobacco smoking has been associated with the occurrence, protraction, and exacerbation of chronically painful conditions. However, consistent with experimental evidence of smoking-related analgesia, there is reason to believe that some smokers may be motivated to use tobacco as a means of coping with their pain. Indeed, researchers have proposed that the avoidance, relief, or both, of pain is a powerful behavioral reinforcer that may be an important mechanism in the maintenance of smoking (Fertig et al., 1986; Jarvik et al., 1989; Pomerleau, 1986; Silverstein, 1982). For example, on questionnaires administered to chronic back pain patients, $57 \%$ of patients acknowledged a need to smoke when in pain, although only $9 \%$ stated that smoking directly affected their pain intensity (Jamison et al., 1991). Additionally, patients were at greater risk for smoking when their pain was most severe. A more recent cross-sectional study found that smokers who suffered from significant pain in the previous week smoked more cigarettes per day than smokers who indicated no significant pain (Hahn, Rayens, Kirsh, \& Passik, 2006). Moreover, $18 \%$ of the respondents who had experienced significant pain in the past week reported using cigarettes for pain relief, compared with $4 \%$ who did not endure significant pain.

There is also evidence of a positive relationship between daily cigarette consumption and the intensity, frequency, and duration of widespread musculoskeletal pain (Andersson et al., 1998; Deyo \& Bass, 1989; Scott et al., 1999), rheumatoid arthritis (Saag et al., 1997), fibromyalgia (Yunus et al., 2002), and oral pain (Riley et al., 2004). 
However, this covariance of pain and smoking may reflect either smokers' use of tobacco to cope with pain, the previously reviewed findings that smoking aggravates painful conditions, or both. That is, the direction of causality is uncertain. To date, experimental research on pain and smoking has focused almost exclusively on tobacco's ability to influence the subjective experience of pain. To our knowledge, there have been no experimental investigations into the effect of pain on smoking motivation. Thus, the primary aim of the present study was to test the hypothesis that laboratoryinduced cold-pressor pain would elicit greater reports of smoking urge and increases in immediate smoking behavior. A secondary aim was to test the hypothesis that the presence of smoking cues (versus neutral cues) would elicit similar increases in smoking motivation, and we explored whether the smoking cues would interact with pain upon these outcomes. Environmental smoking cues such as cigarettes and smoking-related paraphernalia have been found to predict subsequent smoking behavior (Niaura, Abrams, Demuth, Pinto, \& Monti, 1989) and to elicit greater reactivity in smokers when compared with neutral cues (Brandon, Piasecki, Quinn, \& Baker, 1995). The smoking cue manipulation was employed in the current design for two reasons. First, we were unsure as to whether pain would be sufficient to stimulate smoking motivation in the absence of cues signaling the availability of smoking, consistent with Lang's (1984) suggestion that the probability of accessing an affective state (e.g., urge to smoke) is a function of the number of propositions that are matched to the emotion prototype. Second, considering the lack of prior research on pain's capacity to elicit smoking urge, we believed that the smoking cue manipulation would serve as a useful reference point for calibrating the magnitude of the pain manipulation effect. Therefore, pain was induced in the presence of either smoking cues or neutral cues to determine whether smoking cues would produce either an additive or synergistic effect. Finally, we sought 
to examine the influence of potential moderating variables (trait-negative affect, smoking-related outcome expectancies, catastrophizing, ethnicity, and gender) and mediating variables (state-negative affect) in an exploratory manner. 


\section{Method}

\section{Participants}

Newspaper advertisements and flyers were used to recruit 132 smokers (50\% female). The sample size was selected to allow for adequate power ( .80$)$ to detect medium sized $(f=.25)$ main effects at the two-tailed $\alpha=.05$ level (Cohen, 1988). Prospective participants were screened for the following inclusion criteria: between 18 and 65 years of age $(M=36.0 ; S D=11.8)$, smoke at least 20 cigarettes per day $(M=$ 23.2; $S D=6.9$ ), and have a pre-session expired carbon monoxide (CO) concentration of at least $8 p p m(M=23.5 ; S D=11.6)$. Prospective participants were also screened for the following exclusion criteria: the presence of any contraindicative medical conditions (i.e., acute pain, chronic pain, diabetes, epilepsy, and recent injury), and the use of prescription medications for pain management, heart problems, or blood circulation problems. Individuals who failed to meet all of the inclusion criteria or endorsed any of the exclusion criteria were not permitted to participate. Participants had an average Fagerström Test for Nicotine Dependence (Heatherton, Kozlowski, Frecker, \& Fagerstrom, 1991) score of $5.98(S D=2.3)$, indicating that participants in the current sample were moderately to highly dependent on tobacco. The ethnic composition was 73\% Caucasian, 20\% African American, 5\% American Indian or Alaska Native, and 2\% other or unspecified. Thirteen participants (10\%) identified themselves as Hispanic or Latino. Participants were paid a maximum of $\$ 30$ for completing the entire study. 
Design

Participants were randomly assigned to one of four conditions (Pain + Smoking Cue; Pain + Neutral Cue; No Pain + Smoking Cue; No Pain + Neutral Cue), stratified by gender (Riley, Robinson, Wise, Myers, \& Fillingim, 1998), in this 2 (Pain Manipulation) X 2 (Cue Manipulation) crossed factorial between-subjects design. Thus, 33 participants were randomized to each experimental condition.

Measures

Smoking Status Questionnaire (SSQ). This form was used to assess smoking status and nicotine dependence. The SSQ includes the Fagerström Test for Nicotine Dependence, a reliable and valid measure of nicotine dependence (Heatherton et al., 1991).

Questionnaire of Smoking Urges-Brief (QSU-Brief; Cox, Tiffany, \& Christen, 2001). The QSU-Brief is a widely used 10-item urge measure that consists of two 5-item factor-derived subscales (F1: urge to smoke for pleasure/reward, and F2: urge to smoke for the relief of negative affect). Participants indicated how strongly they agreed or disagreed with each item using a Likert-type scale that ranged from 1 (strongly disagree) to 7 (strongly agree), with higher scores indicating stronger smoking urges. The QSU-B Total demonstrated excellent internal consistency $(\alpha=.93)$, as did each of the two factor-derived subscales ( $\alpha=.92$ and $\alpha=.89$, respectively).

Visual Analogue Scale (VAS). A single-item VAS was used to assess smoking urge at four points throughout the study (VAS1, VAS2, VAS3, and VAS4). Participants were asked about the strength of their urge to smoke at that exact moment, and were instructed to make a mark along a $100 \mathrm{~mm}$ line between the phrases "No Urge At All" and "Strongest Urge Ever." The VAS measures of urge were not available for the first three participants in the study. 
Smoking Consequences Questionnaire - Adult (SCQ-A; Copeland, Brandon, \& Quinn, 1995). The SCQ-A was developed and validated for use with adults and is based on the original 50-item Smoking Consequences Questionnaire (Brandon \& Baker, 1991), a standard instrument for measuring smoking-related outcome expectancies.

Participants were administered the following three scales: Scale 1 (a 9-item measure of expectancies for negative affect reduction), Scale 2 (a 7 -item measure of expectancies for state enhancement), and Scale 7 (a 6-item measure of expectancies related to craving and addiction). Each of these scales demonstrated adequate internal consistency, with Cronbach's $\alpha=.92, .86$, and .80, respectively. In addition, a new 5item scale was added to assess smokers' expectancies that smoking would help them cope with pain. This Pain and Smoking Expectancies (PSE) scale demonstrated excellent reliability $(\alpha=.95)$.

Positive And Negative Affect Schedule (PANAS; Watson, Clark, \& Tellegen, 1988). The PANAS is comprised of two orthogonal mood scales (positive and negative), each containing 10 items. This measure was used to assess trait-affect (PANAS-W; mood for the past week) and state-affect (PANAS - I; current mood). Participants were asked to rate their mood on a 5-point Likert scale, ranging from "very slightly or not at all" to "extremely." The ratings of each mood scale were summed, with higher scores indicating stronger affect. The positive and negative affect scales were internally consistent, with Cronbach's $\alpha$ ranging from .90 to .91 and from .82 to .87 , respectively. Pain Catastrophizing Scale (PCS; Sullivan, Bishop, \& Pivik, 1995). The PCS is a 13-item instrument that asks participants to reflect on past painful experiences, and to indicate the degree to which they have each of 13 catastrophizing thoughts or feelings when experiencing pain (e.g., I keep thinking about how badly I want the pain to stop), on 5-point scales. The PCS demonstrated good reliability $(\alpha=.93)$. 
Numerical Rating Scale (NRS; Dworkin et al., 2005). The NRS is an 11-point numerical rating scale of pain intensity. Following pain induction, participants were asked to circle the number that best described their pain, at its worst, since placing their hand in the water.

Smoking behavior. As a behavioral index of smoking motivation, participants were given an opportunity to smoke following the manipulations. Smoking was recorded with a discrete video camera and was later independently scored by two trained raters using a specialized computer program. Latency to smoke (time until cigarette is first lit) was the smoking behavior of primary interest because experimental manipulations of negative affect and anxiety have typically resulted in decreased smoking latency (Conklin \& Perkins, 2005; Payne, Schare, Levis, \& Colletti, 1991; Rose, Ananda, \& Jarvik, 1983). Behavioral variables of secondary interest included: number of puffs, mean puff duration, mean interpuff interval, and total time spent smoking.

\section{Manipulations}

Cold Pressor. The cold pressor procedure has been used in numerous studies investigating a wide range of pain-related outcomes. This method of pain stimulation is thought to share some subjective qualities frequently observed in clinical pain patients because of its potential to mimic the unpleasantness experienced by individuals with chronically painful conditions (Keogh, Hatton, \& Ellery, 2000; Rainville, Feine, Bushnell, \& Duncan, 1992). All participants were told that the maximum cold-pressor tolerance time would be limited to five minutes. Participants in the Pain $(P)$ induction conditions were asked to immerse their non-dominant hand into a circulating cold-water bath $\left(0-1^{\circ}\right.$ Celsius) until they felt it was too uncomfortable to continue. Participants in the No Pain (NP) conditions were asked to immerse their non-dominant hand into a room temperature bath until they felt it was too uncomfortable to continue. However, these NP 
participants were prompted to remove their hand after 100 seconds to approximate the tolerance times of participants in the $\mathrm{P}$ conditions. The 100 -second submersion limit for participants in the NP conditions was derived from mean tolerance times reported in a recent review of cold pressor methodology (Mitchell, MacDonald, \& Brodie, 2004). Both the cold and room temperature cold pressors were identical insulated cooler units consisting of a perforated screen (to separate the water and ice) and a 12-volt bilge pump (to circulate the water).

Smoking Cue. To test the hypothesis that the presence of smoking cues (SC) as compared to neutral cues (NC) during and following the experience of pain would lead to increased motivation to smoke, all participants underwent the pain manipulation and completed post-test questionnaires with either a SC or NC in their view. The SC consisted of participants' own pack of cigarettes, a lighter, and an ashtray (with one cigarette removed from their pack and placed in the ashtray). The NC consisted of similarly placed, sized, and shaped office supplies (e.g., box of staples, roll of tape, a staple remover, and a pencil).

Procedure

Overview. This study was conducted in two parts during one session that lasted approximately 80 minutes. Part one consisted of screenings and baseline measures, whereas part two included the pain manipulation (P or NP), the cue manipulation (SC or NC), post-test measures, and observation of smoking behavior. As approved by the university institutional review board, we employed a two-part consent process to ensure that anticipatory anxiety related to undergoing a cold pressor task would not influence baseline measures. Although participants were told upfront that this was a one-session, two-part study, there was no mention of the pain manipulation until the second informed consent was presented and explained (i.e., after baseline measures were completed). 
This rationale was fully explained to participants before they were asked if they wanted to proceed with the study.

Part One. To standardize smoking behavior prior to the experiment, all participants were asked to smoke one cigarette one hour before their appointment, and none thereafter. They were also asked to refrain from using any non-prescription pain medications for 24 hours prior to their appointment. On arrival, participants were reminded that this was a two-part study, and they were told that the fist informed consent applied only to the first part of the study. After informed consent was obtained, participants were asked how long it had been since their last cigarette, and breath CO level was measured with a Vitalograph CO monitor (Vitalograph, Lenexa, KS). Those who reportedly failed to follow the standardized smoking instructions or had CO levels below 8 ppm were excused from the study $(n=9)$. Participants then completed baseline measures (SSQ, QSU-Brief, VAS1, SCQ-A, PSE, PANAS-W, PANAS-I, and the PCS).

Second Informed Consent. After participants completed the baseline measures, they were told they had already earned $\$ 15$ for completing the first part of the study and that they were under no obligation to continue with the experiment. Participants were then informed that the second part of this study was designed to investigate their pain threshold and tolerance, and that they would be randomly assigned to place their hand into either a room temperature water bath or a cold water bath. Participants were further informed that if they were assigned to place their hand in cold water, they would only be asked to do so until they found it too uncomfortable to continue. The experimenter described the cold pressor procedure in detail and provided rationale for conducting the study in two parts. None of the participants declined to proceed with the study. Once the second informed consent was obtained, the experimenter administered a second measure of smoking urge (VAS2) to assess the influence of anticipatory anxiety on 
smoking motivation. Participants were then randomly assigned to one of four conditions $(P+S C, P+N C, N P+S C, N P+N C)$, stratified by gender. Note that both experimenters and participants were blind to condition assignment until this point.

Part Two. After participants were randomized to their respective conditions, they were led to an experimental room consisting of a table, a chair, and both cold pressor units, arranged in accordance with their non-dominant hand (i.e., the table was on the side of their dominant hand and the cold pressors were on the side of their non-dominant hand). At this point, the cue reactivity manipulation was introduced. Participants in the SC conditions had their own cigarettes, an ashtray, and a lighter placed on the table next to them and were told that they would be able to smoke soon. Anticipation of a smoking opportunity has been found to enhance cue-reactivity (e.g., Juliano \& Brandon, 1998; Wertz \& Sayette, 2001). Participants in the NC conditions had similarly placed, sized, and shaped office supplies placed on the table next to them and were told nothing about when they would be able to smoke. Once the appropriate cue was in place, participants were again provided with the cold pressor instructions and reassured concerning the safety of the procedure. To standardize limb temperature and reduce the chance of alterations in vasoconstriction influencing the results, each participant first immersed his/her non-dominant hand in the room temperature bath for two minutes. Immediately afterward, the same hand was immersed up to $7 \mathrm{~cm}$ above the wrist bone into either the cold-water bath (Pain conditions) or back into the room temperature bath (No Pain conditions). Only at this point did participants become aware of what condition they were in ( $P$ vs. NP). Participants were instructed to inform the experimenter when the sensations in their hand first became painful (pain threshold) and to also indicate when they were no longer willing or able to tolerate the pain by removing their hand (pain tolerance). Immediately after participants in the $\mathrm{P}$ conditions reported reaching their pain 
threshold, the experimenter administered a third measure of smoking urge (VAS3) to assess craving during the experience of pain. Participants in the NP conditions were asked to complete VAS3 approximately 10 seconds after they submerged their hand back into the room temperature bath.

Post-Test. Once participants removed their hand from the water (pain tolerance for the $\mathrm{P}$ group and 100 seconds for the NP group) they were asked to lay their nondominant hand across the cold pressor and immediately complete the post-test measures with their dominant hand (NRS, QSU-Brief, VAS4, and PANAS-I). When these measures were collected, participants were provided with paper towels to dry their hand. Once the paper towels were disposed of, the experimenter either motioned to the smoking cues by shifting them slightly (SC conditions), or replaced the neutral cues with smoking cues that were hidden in the room (NC conditions). All participants were then told that they were welcome to smoke as much of one cigarette as they would like, but to please take at least one puff. The experimenter concluded by informing participants that he/she would return in about 10 minutes. The experimenter then left the room and the participant was videotaped smoking the cigarette. When the experimenter returned, participants provided a second CO sample, were debriefed, and were compensated for their time. 


\section{Results}

\section{Baseline Measures}

There were no significant differences among the four groups on baseline measures of smoking urge, negative affect, and pain catastrophizing (all $p s>.05$ ). Analyses did reveal unexpected group differences on the second urge measure (VAS2), with participants in the $\mathrm{P}$ conditions reporting significantly greater urge to smoke than participants in the NP conditions, $F(3,125)=30.30, p<.01$. The reason for these group differences remains unclear, however, because both participants and experimenters were blind to condition assignment when the measure was administered (i.e., randomization had not yet taken place). Accordingly, ANCOVAs were conducted in all subsequent urge analyses to statistically control for group differences on VAS2 that occurred prior to randomization.

Manipulation Checks: Pain Intensity and Negative Affect

As expected, participants in the $\mathrm{P}$ conditions reported much greater pain intensity $(M=7.79 ; S E=.19)$ than participants in the NP conditions $(M=.46 ; S E=.19)$, as measured by the NRS, $F(3,128)=736.65, p<.001$, effect size $f=2.38$. Also as expected, participants in the $\mathrm{P}$ conditions reported greater state-negative affect $(M=$ 16.86; SE $=.71)$ than participants in the NP conditions $(M=14.47 ; S E=.71)$ following the pain manipulation, $F(3,128)=5.76, p=.02, f=.21$.

\section{Primary Analyses}

Smoking Urge. To examine group differences on self-report measures of smoking urge, $2 \times 2$ analyses of covariance were conducted, with the pain manipulation 
(P vs. NP) and cue type (SC vs. NC) as the two fixed factors, and pre-manipulation urge to smoke (VAS2) as the covariate. Interactions between the two fixed factors were tested for synergistic effects. Effect sizes, indexed as $f$, were calculated for significant $F$ tests. According to Cohen (1988), $f$ values of $.10, .25$, and .40 can be considered small, medium, and large, respectively.

Analysis of overall post-test urge to smoke (QSU-Brief Total) indicated a main effect of the pain manipulation, $F(4,124)=18.75, p<.001, f=.39$. Urge ratings were significantly higher for participants who experienced situational pain $(P)$ than for participants who did not experience pain (NP). Analysis also revealed a main effect of cue type, $F(4,124)=4.20, p=.04, f=.18$, such that urge ratings were higher when participants were exposed to smoking cues (SC) than when exposed to neutral cues (NC). The pain manipulation $x$ cue type interaction was not significant $(p=.55)$. Thus, the effects of pain and smoking cues were additive rather than synergistic. A main effect of the pain manipulation was also found for a secondary measure of post-test urge to smoke (VAS4), $F(4,124)=5.70, p=.02, f=.21$. Covariate adjusted means and standard errors for all post-test urge measures are presented in Table 1.

Smoking Behavior. Similar $2 \times 2$ analyses of variance were conducted, with the pain manipulation and cue type as the two fixed factors, and measures of immediate smoking behavior (e.g., latency to smoke, number of puffs, puff duration) as the dependent variables. Based on the observations of two independent raters, the data for 10 participants $(7.5 \%)$ were excluded from the latency analysis either because of experimenter error (e.g., participants cued to smoke too early in the procedure) $(n=4)$, or because the participant encountered a disruptive confound (e.g., broken cigarette or lighter) $(n=6)$. These participants were fairly balanced across experimental conditions with six assigned to P conditions and four assigned to NP conditions. Finally, the data 
from two participants (one each from the $\mathrm{P}$ and NP conditions) were excluded as outliers from analyses related to puffing, because the number of puffs they took exceeded three standard deviations from the mean.

Analysis of latency to light a cigarette following the pain manipulation revealed a main effect of pain induction, $F(3,118)=5.73, p=.02, f=.21$, with participants in the $\mathrm{P}$ conditions demonstrating significantly shorter latency to smoke than participants in the NP conditions. No significant differences in latency to smoke as a function of cue type were found, $F(3,118)=.30, p=.59$. Latency means and standard errors for each of the four experimental conditions are presented in Table 1. Analysis of secondary measures of smoking behavior (i.e., number of puffs, mean puff duration, mean interpuff interval, and total time spent smoking) indicated no significant main effects (all ps > .05). Additional Analyses

QSU-Brief Subscales. In addition to the QSU-Brief Total, the two QSU-Brief factor-derived subscales (F1: urge to smoke for pleasure/reward, and F2: urge to smoke for the relief of negative affect) were examined for group differences. Analyses indicated a main effect of the pain manipulation (P vs. NP) for both QSU-Brief $F 1[F(4,124)=$ $15.99, p<.001, f=.12]$ and QSU-Brief F2 $[F(4,124)=12.37, p=.001, f=.32]$, with greater urges reported by participants who underwent pain induction. Analyses also indicated a main effect of cue type (SC vs. NC), but only for QSU-Brief F2 $[F(4,124)=$ $4.61, p=.03, f=.19]$, with greater urges to smoke for the relief of negative affect reported by participants in the SC conditions. There were no pain manipulation $\mathrm{x}$ cue type interactions (both $p s>.21$ ).

Smoking urge during the pain manipulation. Analysis of urge ratings (VAS3) during the pain manipulation (i.e., while the participant's hand was still immersed in the cold water bath) revealed a main effect for pain induction, $F(3,125)=10.90, p=.001, f$ 
$=.29$. As hypothesized, urge to smoke during the pain manipulation was greater for participants in the P conditions than for participants in the NP conditions. The main effect for cue type (SC vs. NC) did not reach significance, $F(3,125)=3.03, p=.08$. See Table 1 for means and standard errors. 
Table 1

Marginal Means (and Standard Errors) for Post-Test Measures of Smoking Motivation

\begin{tabular}{|c|c|c|c|c|c|c|c|c|c|c|}
\hline & \multicolumn{2}{|c|}{ No Pain Conditions } & \multicolumn{2}{|c|}{ Pain Conditions } & \multicolumn{2}{|c|}{ Pain Manipulation } & & \multicolumn{2}{|c|}{ Cue Manipulation } & \\
\hline & NC & SC & NC & SC & $P$ & NP & & NC & SC & \\
\hline QSU-B T ${ }^{\mathrm{a}}$ & $37.02(1.82)$ & $39.67(1.81)$ & $44.12(1.83)$ & $48.96(1.89)$ & $38.34(1.30)$ & $46.54(1.33)$ & ** & $40.57(1.28)$ & $44.31(1.30)$ & $\bar{*}$ \\
\hline QSU-B F1 ${ }^{\mathrm{a}}$ & $22.84(0.98)$ & $24.47(0.97)$ & $27.22(0.98)$ & $28.20(1.01)$ & $23.65(0.70)$ & $27.71(0.71)$ & ** & $25.03(0.69)$ & $26.33(0.69)$ & \\
\hline QSU-B F2 ${ }^{\mathrm{a}}$ & $14.18(1.13)$ & $15.20(1.12)$ & $16.90(1.14)$ & $20.80(1.18)$ & $14.69(0.81)$ & $18.83(0.83)$ & $* *$ & $15.54(0.80)$ & $17.98(0.81)$ & * \\
\hline VAS $3^{\mathrm{b}}$ & $47.30(4.66)$ & $51.70(4.66)$ & $59.06(4.74)$ & $71.10(4.81)$ & $49.50(3.30)$ & $65.08(3.38)$ & ** & $53.18(3.32)$ & $61.40(3.35)$ & \\
\hline $\operatorname{VAS} 4^{\mathrm{a}}$ & $55.93(3.63)$ & $57.81(3.60)$ & $62.92(3.70)$ & $68.82(3.77)$ & $56.87(2.58)$ & $65.87(2.65)$ & * & $59.42(2.56)$ & $63.31(2.58)$ & \\
\hline Latency $^{\mathrm{b}}$ & $3.88(0.69)$ & $5.19(0.70)$ & $3.10(0.69)$ & $2.57(0.75)$ & $4.53(0.49)$ & $2.84(0.51)$ & * & $3.49(0.49)$ & $3.88(0.52)$ & \\
\hline
\end{tabular}

Note. $\mathrm{NC}=$ neutral cue conditions. $\mathrm{SC}=$ smoking cue conditions. $\mathrm{P}=$ pain induction conditions. NP $=$ no pain induction conditions. $\mathrm{QSU}-\mathrm{B}$ $\mathrm{T}=$ mean scores on the total QSU-Brief measure of smoking urge administered post-pain manipulation. QSU-B F1 = mean scores on

Factor 1 of the QSU-Brief (urge to smoke for pleasure/reward). QSU-B F2 = mean scores on Factor 2 of the QSU-Brief (urge to smoke for the relief of negative affect). VAS $3=$ mean scores on a visual analogue scale of smoking urge administered during the pain manipulation.

VAS 4 = mean scores on a visual analogue scale of smoking urge administered post-pain manipulation. Latency = mean latency to light a cigarette post-pain manipulation (in seconds).

${ }^{\mathrm{a}}$ Covariate (VAS2) adjusted means and standard errors. ${ }^{\mathrm{b}}$ Unadjusted means and standard errors.

${ }^{*} p<.05 .{ }^{* *} p<.01$., for main effects of the pain and cue manipulations, respectively. 
Mediation. Mediation analyses were conducted to examine whether situational pain indirectly enhanced smoking urge by increasing levels of state negative affect (NA). Formal significance tests of the indirect effect of NA were conducted by means of the Sobel test (1982) and a bootstrap approach (Efron \& Tibshirani, 1993), as described by Preacher \& Hayes (2004). Results of both procedures indicated that the indirect effect of pain induction on urge to smoke through increased NA was significantly different from zero $(p<.05)$. To further examine the degree of mediation, a four-step, ordinary least squares approach was employed (Baron \& Kenny, 1986). According to Baron and Kenny (1986), if all four steps are met, the data are consistent with the hypothesis that variable $M$ completely mediates the $X-Y$ relationship, and if the first three steps are met but the fourth step is not, then partial mediation is indicated. Analyses revealed the following: Step 1 indicated a significant total effect of pain induction on urge to smoke $\left(B=.43, R^{2}\right.$ $=.19, p<.001)$; Step 2 indicated a significant effect of pain induction on NA $\left(ß=.21, R^{2}\right.$ $=.04, p=.02$ ); and Step 3 indicated a significant effect of NA on urge to smoke, while controlling for pain induction $\left(B=.32, s r^{2}=.096, p<.001\right)$. Thus, the first three steps in establishing mediation were satisfied, supporting the results of our tests of the indirect effect. Step 4, however, revealed that although the total effect of pain induction on smoking urge decreased when controlling for $N A$, it remained significant $\left(ß=.37, s r^{2}=\right.$ $.129, p<.001)$, indicating that NA partially mediated this relationship. These results demonstrate that pain induction and pain-induced NA, collectively, accounted for $28 \%$ of the variance $\left(R^{2}=.28\right)$ in self-reported urge to smoke. Of this, pain induction uniquely accounted for $13 \%$, NA uniquely accounted for $9.5 \%$, and approximately $5.5 \%$ of the variance was shared. Thus, NA accounted for approximately $30 \%$ of the total effect of pain induction on urge to smoke $(5.5 \% / 18.5 \%)$. Finally, analyses revealed no evidence that NA mediated the effect of pain induction on latency to smoke (all $p s>.11$ ). 
Moderation. Several potential moderators of the relationship between pain and smoking motivation (trait-negative affect, smoking-related outcome expectancies, catastrophizing, ethnicity, and gender) were explored via interaction tests using multiple regression (Baron \& Kenny, 1986). No significant interactions were found.

Pain threshold and tolerance, gender, and urge to smoke. Pain threshold and tolerance times, and ratings of pain intensity were examined to determine whether the pain manipulation was equivalent for the SC and NC conditions, and to determine whether magnitude of pain reactivity was correlated with urge ratings within the $P$ conditions. Gender was tested as a potential moderator of the observed group differences in urge to smoke. Because pain threshold and tolerance variables were significantly positively skewed (pain threshold skewness $=2.87$, pain tolerance skewness $=1.96)$, we performed logarithmic transformations. One male participant was treated as an outlier and excluded from the analysis because he obtained a tolerance score (305s) that was greater than three standard deviations from the mean. As expected based on prior research, we found significant gender differences in pain threshold and tolerance times. Specifically, men demonstrated greater pain threshold times than women, $M=11.59 \mathrm{~s}(S D=8.19 \mathrm{~s})$ vs. $M=5.98 \mathrm{~s}(S D=2.72 \mathrm{~s}) ; t(63)=4.65, p$ $<.001$. Men also demonstrated greater pain tolerance times than women, $M=21.92 \mathrm{~s}$ $(S D=11.86 \mathrm{~s})$ vs. $M=15.718 \mathrm{~s}(S D=7.89 \mathrm{~s}) ; t(63)=2.69, p<.01$. However, gender did not moderate the observed group differences in urge to smoke following the pain manipulation $(p=.92)$. There were also no differences in ratings of pain intensity or threshold and tolerance times as a function of cue type (SC vs. NC), indicating that the pain manipulation was equivalent across these conditions ( $p s>.75)$. Finally, magnitude of pain reactivity (i.e., ratings of pain intensity, and pain threshold and tolerance times) was not correlated with urge to smoke within the $\mathrm{P}$ conditions. 


\section{Discussion}

The main goal of this study was to determine whether situational pain was sufficient to increase smoking motivation, as indexed by self-reported urge to smoke and observation of immediate smoking behavior. As hypothesized, participants who experienced situational pain reported significantly greater smoking urges and demonstrated shorter latency to smoke following experimental pain induction than participants who did not experience pain.

As reviewed earlier, almost all research into the relationship between tobacco use and chronic pain has focused on the effects of smoking on pain (i.e., smoking exacerbating underlying pain conditions or smoking inhibiting acute episodes of pain). An alternative approach within this line of research is to examine the effects of pain on smoking. For example, the obvious health implications of smoking causing or exacerbating chronic pain could only be compounded if smokers are at risk for increasing their smoking behavior when experiencing periods of heightened pain intensity. Some cross-sectional evidence does indicate that smokers with chronic pain report a need to smoke when in pain, and this study provides the first experimental evidence that situational pain is a causal motivator of smoking. By integrating these two research directions, comprising the literature to date, we conceptualize a potentially reciprocal relationship between pain and smoking. As illustrated in Figure 1, we propose that smokers who are motivated to use tobacco to cope with or assuage pain may unwittingly aggravate their painful condition by increasing their cigarette consumption, thus engendering a vicious cycle that could lead to greater nicotine dependence. 
Figure 1. Conceptualization of the proposed reciprocal relationship between pain and smoking

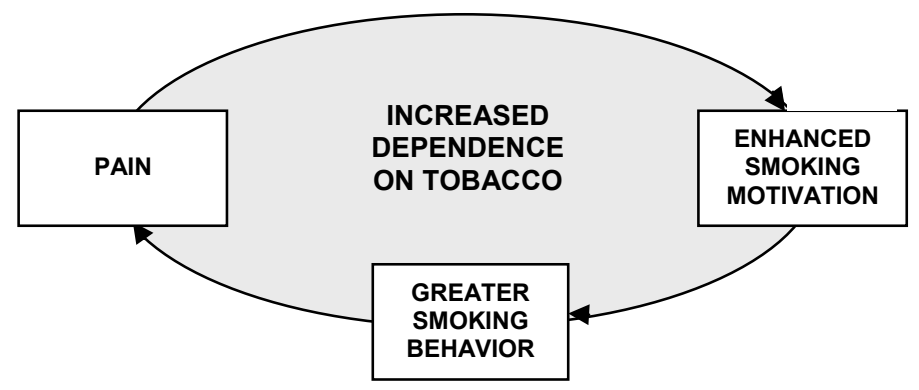

Interestingly, the demonstrated causal relationship between pain and enhanced smoking motivation was only partially mediated by pain-induced state-negative affect. This finding suggests that pain may be a potent motivator of smoking, mostly independent of putative mood effects (i.e., increased negative affect). Indeed, approximately $70 \%$ of the variance in the direct effect of pain induction on increased urge to smoke remains unexplained. It is plausible that this relationship may also be partially mediated by other psychological or physiological factors that were not detected, measured, or manipulated in the current study such as the activation of smoking-related or pain-related self-efficacy and outcome expectancies and the execution of pain-related coping behaviors.

Although several potential moderators of the relationship between pain and increased smoking motivation were explored, no significant interactions were revealed. Cognitive variables such as expectancies that smoking reduces pain and the tendency to catastrophize about pain did not predispose our participants toward smoking when in pain. It may be that the processes measured by these instruments do not apply as well to artificially-induced acute pain as compared to recurring chronic pain. That is, among smokers who rarely need to cope with pain, as in the present sample, the questions may have been too hypothetical. A chronic pain sample might produce different findings. 
Additionally, these measurements may be more valid when collected during periods of acute pain.

Our finding that men evidenced greater pain threshold and tolerance times than women is in accord with previous research that consistently demonstrates significant pain-related gender differences (Berkley, 1997; Girdler et al., 2005; Myers, Riley, \& Robinson, 2003). However, we observed no significant gender differences in urge to smoke following pain-induction, suggesting that although gender may play an important role in pain reporting, exposure to a painful experience may be sufficient to increase smoking urge regardless of whether the smoker is male or female. The lack of an association between indices of pain reactivity and urge ratings within the pain induction conditions, suggests that - at least with respect to the cold-pressor paradigm - there is not a dose-response effect of pain. That is, acute pain produced increased urges to smoke regardless of the perceived pain magnitude.

We also explored whether the presence and availability of smoking cues (versus neutral cues) would interact with pain upon outcomes related to smoking motivation. Although the pain by cue type interactions did not reach significance, urge ratings were significantly higher in the presence of smoking cues relative to neutral cues. This finding indicates additive, not synergistic, effects of pain and smoking cues on self-reported urge to smoke. Latency to smoke, however, was not shorter in the presence of smoking cues, perhaps suggesting that the painful experience overwhelmed the influence of cue type once participants were given the opportunity to smoke a cigarette.

The main limitation of the current study is that these findings do not necessarily generalize to individuals who suffer from chronic pain. Although the cold-pressor method of pain stimulation may share some subjective qualities frequently observed in clinical pain patients (Keogh et al., 2000; Rainville et al., 1992), there is no question that 
experimentally-induced acute pain is not equivalent to the daily pain endured by people with chronic conditions. However, we felt that subjecting chronic pain patients to experimental pain induction at this early stage of hypothesis testing was unnecessary and possibly inappropriate. In addition to ethical concerns, a laboratory pain paradigm was selected to allow for increased experimental control and enhanced feasibility. A second limitation is the potential influence of demand effects. Whereas it is conceivable that participants may have recognized that self-reported urges to smoke were hypothesized to increase following pain induction, it is more difficult to attribute the observed group differences on the behavioral measure of smoking motivation (i.e., latency to smoke) to demand effects. A third limitation of the current findings is the limited power to detect significant moderator interactions. Although we only intended to examine the influence of potential moderating variables in an exploratory manner, future investigations may benefit from focusing on this aspect of the casual association between pain and smoking motivation to help elucidate important underlying mechanisms. Indeed, some potential moderating variables (e.g., coping behaviors; selfefficacy and outcome expectancies) could be tested via experimental manipulation.

Future studies could also examine the potential for a dose-response relationship between pain and smoking motivation. For example, one investigation of the relationship between cold-pressor water temperature and pain tolerance and intensity concluded that small reductions in water temperature resulted in significantly reduced tolerance times and increased ratings of pain intensity (Mitchell et al., 2004). It would be interesting to know if smoking motivation increased as a function of pain intensity or duration of the painful experience. Another possibility is to examine differences in pain-induced smoking motivation as a function of pain modality (e.g., cold pressor, thermal heat, electrical stimulation, tourniquet ischemia), some of which may be closer analogues to chronic 
pain. Indeed, the nature of the noxious stimulus used to induce pain has been shown to impact pain sensitivity (Girdler et al., 2005; Rainville et al., 1992). Finally, future research should investigate the temporal relationship between pain and smoking motivation in naturalistic (i.e., real-world) settings, perhaps using ecological momentary assessment (Stone \& Shiffman, 1994).

In summary, this study provides the first experimental evidence that situational pain is a potent motivator of smoking, partially mediated by pain-induced negative affect. That smokers are motivated to use tobacco in response to pain raises the possibility that smokers with painful conditions could develop unique dependence profiles. We believe that a systematic analysis of the causal link between pain and smoking motivation is an appropriate next step in this line of research. Smoking appears to be a prominent feature of painful conditions, and tobacco dependence may provide an invaluable model for research on addictive behaviors in the chronic pain population. 


\section{References}

Aceto, M. D., Bagley, R. S., Dewey, W. L., Fu, T. C., \& Martin, B. R. (1986). The spinal cord as a major site for the antinociceptive action of nicotine in the rat. Neuropharmacology, 25, 1031-1036.

Al-Wahadni, A., \& Linden, G. J. (2002). Dentine hypersensitivity in Jordanian dental attenders. A case control study. Journal of Clinical Periodontology, 29, 688-693.

Albano, S. A., Santana-Sahagun, E., \& Weisman, M. H. (2001). Cigarette smoking and rheumatoid arthritis. Seminars in Arthritis and Rheumatism, 31, 146-159.

American Pain Society. (2003). Principles of analgesic use in the treatment of acute pain and cancer pain (5th ed.). Glenview, IL: Author.

Andersson, H., Ejlertsson, G., \& Leden, I. (1998). Widespread musculoskeletal chronic pain associated with smoking. An epidemiological study in a general rural population. Scandinavian Journal of Rehabilitation Medicine, 30, 185-191.

Baron, R. M., \& Kenny, D. A. (1986). The moderator-mediator variable distinction in social psychological research: conceptual, strategic, and statistical considerations. Journal of Personality and Social Psychology, 51, 1173-1182.

Beck, E., Sieber, W. J., \& Trejo, R. (2005). Management of cluster headache. American Family Physician, 71, 717-724.

Berkley, K. J. (1997). Sex differences in pain. Behavioral and Brain Sciences, 20, 371380; discussion 435-513.

Biering-Sorensen, F., \& Thomsen, C. (1986). Medical, social and occupational history as risk indicators for low-back trouble in a general population. Spine, 11, 720-725. 
Brage, S., \& Bjerkedal, T. (1996). Musculoskeletal pain and smoking in Norway. Journal of Epidemiology and Community Health, 50, 166-169.

Brandon, T. H., \& Baker, T. B. (1991). The Smoking Consequences Questionnaire: The subjective expected utility of smoking in college students. Psychological Assessment, 3, 484-491.

Brandon, T. H., Piasecki, T. M., Quinn, E. P., \& Baker, T. B. (1995). Cue exposure treatment in nicotine dependence. In C. D. Drummond \& S. T. Tiffany (Eds.), Addictive behaviour: Cue exposure theory and practice. The Wiley series in clinical psychology. (pp. 211-227). New York: Wiley.

CDC. (2005). Cigarette Smoking Among Adults - United States, 2004. MMWR Morbidity and Mortality Weekly Report, 54, 1121-1124.

Cohen, J. (1988). Statistical power analysis for the behavioral sciences (2nd Ed.). Hillsdale, NJ: Erlbaum.

Conklin, C. A., \& Perkins, K. A. (2005). Subjective and reinforcing effects of smoking during negative mood induction. Journal of Abnormal Psychology, 114, 153-164.

Cooley, J. E., Villarosa, G. A., Lombardo, T. W., Moss, R. A., Fowler, S. C., \& Sult, S. (1990). Effect of pCPA on nicotine-induced analgesia. Pharmacology, Biochemistry and Behavior, 36, 413-415.

Copeland, A. L., Brandon, T. H., \& Quinn, E. P. (1995). The Smoking Consequences Questionnaire-Adult: measurement of smoking outcome expectancies of experienced smokers. Psychological Assessment, 7, 484-494.

Cox, L. S., Tiffany, S. T., \& Christen, A. G. (2001). Evaluation of the brief questionnaire of smoking urges (QSU-brief) in laboratory and clinical settings. Nicotine \& Tobacco Research, 3, 7-16. 
Creekmore, F. M., Lugo, R. A., \& Weiland, K. J. (2004). Postoperative opiate analgesia requirements of smokers and nonsmokers. Annals of Pharmacotherapy, 38, 949953.

Deyo, R. A., \& Bass, J. E. (1989). Lifestyle and low-back pain. The influence of smoking and obesity. Spine, 14, 501-506.

Dworkin, R. H., Turk, D. C., Farrar, J. T., Haythornthwaite, J. A., Jensen, M. P., Katz, N. P., et al. (2005). Core outcome measures for chronic pain clinical trials: IMMPACT recommendations. Pain, 113, 9-19.

Efron, B., \& Tibshirani, R. J. (1993). An introduction to the bootstrap. Boca Raton, FL: Chapman \& Hall.

Eriksen, W. B., Brage, S., \& Bruusgaard, D. (1997). Does smoking aggravate musculoskeletal pain? Scandinavian Journal of Rheumatology, 26, 49-54.

Fertig, J. B., Pomerleau, O. F., \& Sanders, B. (1986). Nicotine-produced antinociception in minimally deprived smokers and ex-smokers. Addictive Behaviors, 11, 239248.

Frymoyer, J. W., Pope, M. H., Costanza, M. C., Rosen, J. C., Goggin, J. E., \& Wilder, D. G. (1980). Epidemiologic studies of low-back pain. Spine, 5, 419-423.

Ghandour, R. M., Overpeck, M. D., Huang, Z. J., Kogan, M. D., \& Scheidt, P. C. (2004). Headache, stomachache, backache, and morning fatigue among adolescent girls in the United States: associations with behavioral, sociodemographic, and environmental factors. Archives of Pediatrics and Adolescent Medicine, 158, 797803.

Girdler, S. S., Maixner, W., Naftel, H. A., Stewart, P. W., Moretz, R. L., \& Light, K. C. (2005). Cigarette smoking, stress-induced analgesia and pain perception in men and women. Pain, 114, 372-385. 
Glasson, J. C., Sawyer, W. T., Lindley, C. M., \& Ginsberg, B. (2002). Patient-specific factors affecting patient-controlled analgesia dosing. Journal of Pain \& Palliative Care Pharmacotherapy, 16, 5-21.

Hagg, O., Fritzell, P., \& Nordwall, A. (2002). Characteristics of patients with chronic low back pain selected for surgery: a comparison with the general population reported from the Swedish lumbar spine study. Spine, 27, 1223-1231.

Hahn, E. J., Rayens, M. K., Kirsh, K. L., \& Passik, S. D. (2006). Brief report: Pain and readiness to quit smoking cigarettes. Nicotine \& Tobacco Research, 8, 473-480.

Harrison, B. J., \& Silman, A. J. (2000). Does smoking influence disease outcome in patients with rheumatoid arthritis? Journal of Rheumatology, 27, 569-570.

Heatherton, T. F., Kozlowski, L. T., Frecker, R. C., \& Fagerstrom, K. O. (1991). The Fagerstrom Test for Nicotine Dependence: a revision of the Fagerstrom Tolerance Questionnaire. British Journal of Addiction, 86, 1119-1127.

Hutchinson, D., Shepstone, L., Moots, R., Lear, J. T., \& Lynch, M. P. (2001). Heavy cigarette smoking is strongly associated with rheumatoid arthritis (RA), particularly in patients without a family history of RA. Annals of the Rheumatic Diseases, 60, 223-227.

Jamison, R. N., Stetson, B. A., \& Parris, W. C. (1991). The relationship between cigarette smoking and chronic low back pain. Addictive Behaviors, 16, 103-110. Jamner, L. D., Girdler, S. S., Shapiro, D., \& Jarvik, M. E. (1998). Pain inhibition, nicotine, and gender. Experimental and Clinical Psychopharmacology, 6, 96-106.

Jarvik, M. E., Caskey, N. H., Rose, J. E., Herskovic, J. E., \& Sadeghpour, M. (1989). Anxiolytic effects of smoking associated with four stressors. Addictive Behaviors, 14, 379-386. 
John, U., Alte, D., Hanke, M., Meyer, C., Volzke, H., \& Schumann, A. (2006). Tobacco smoking in relation to analgesic drug use in a national adult population sample. Drug and Alcohol Dependence, 85, 49-55.

Johnson, G. K., \& Slach, N. A. (2001). Impact of tobacco use on periodontal status. Journal of Dental Education, 65, 313-321.

Juliano, L. M., \& Brandon, T. H. (1998). Reactivity to instructed smoking availability and environmental cues: evidence with urge and reaction time. Experimental and Clinical Psychopharmacology, 6, 45-53.

Kanarek, R. B., \& Carrington, C. (2004). Sucrose consumption enhances the analgesic effects of cigarette smoking in male and female smokers. Psychopharmacology, 173, 57-63.

Keogh, E., Hatton, K., \& Ellery, D. (2000). Avoidance versus focused attention and the perception of pain: differential effects for men and women. Pain, 85, 225-230.

Kinane, D. F., \& Chestnutt, I. G. (2000). Smoking and periodontal disease. Critical Reviews in Oral Biology and Medicine, 11, 356-365.

Knott, V. J. (1990). Effects of cigarette smoking on subjective and brain evoked responses to electrical pain stimulation. Pharmacology, Biochemistry and Behavior, 35, 341-346.

Krishnan, E., Sokka, T., \& Hannonen, P. (2003). Smoking-gender interaction and risk for rheumatoid arthritis. Arthritis Research and Therapy, 5, R158-162.

Lane, J. D., Lefebvre, J. C., Rose, J. E., \& Keefe, F. J. (1995). Effects of cigarette smoking on perception of thermal pain. Experimental and Clinical Psychopharmacology, 3, 140-147. 
Lang, P. J. (1984). Cognition in emotion: Concept and action. In C. Izzard, J. Kaga \& R. Zajonc (Eds.), Emotions, cognition, and behavior (pp. 128-200). New York: Cambridge University Press.

Leino-Arjas, P. (1998). Smoking and musculoskeletal disorders in the metal industry: a prospective study. Occupational and Environmental Medicine, 55, 828-833.

Lindal, E., \& Stefansson, J. G. (1996). Connection between smoking and back pain-findings from an Icelandic general population study. Scandinavian Journal of Rehabilitation Medicine, 28, 33-38.

Mitchell, L. A., MacDonald, R. A., \& Brodie, E. E. (2004). Temperature and the cold pressor test. Journal of Pain, 5, 233-237.

Mousa, S. A., Aloyo, V. J., \& Van Loon, G. R. (1988). Tolerance to tobacco smoke- and nicotine-induced analgesia in rats. Pharmacology, Biochemistry and Behavior, 31, 265-268.

Myers, C. D., Riley, J. L., 3rd, \& Robinson, M. E. (2003). Psychosocial contributions to sex-correlated differences in pain. Clinical Journal of Pain, 19, 225-232.

Nesbitt, P. D. (1973). Smoking, physiological arousal, and emotional response. Journal of Personality and Social Psychology, 25, 137-144.

Niaura, R. S., Abrams, D., Demuth, B., Pinto, R., \& Monti, P. (1989). Responses to smoking-related stimuli and early relapse to smoking. Addictive Behaviors, 14, 419-428.

Nuprin. (1985). Nuprin Pain Report. New York: Louis Harris \& Associates, Inc.

Palmer, K. T., Syddall, H., Cooper, C., \& Coggon, D. (2003). Smoking and musculoskeletal disorders: findings from a British national survey. Annals of the Rheumatic Diseases, 62, 33-36. 
Patel, N., Talwar, A., Reichert, V. C., Brady, T., Jain, M., \& Kaplan, M. H. (2006). Tobacco and HIV. Clin Occup Environ Med, 5, 193-207, xi.

Pauli, P., Rau, H., Zhuang, P., Brody, S., \& Birbaumer, N. (1993). Effects of smoking on thermal pain threshold in deprived and minimally-deprived habitual smokers. Psychopharmacology, 111, 472-476.

Payne, T. J., Schare, M. L., Levis, D. J., \& Colletti, G. (1991). Exposure to smokingrelevant cues: effects on desire to smoke and topographical components of smoking behavior. Addictive Behaviors, 16, 467-479.

Payne, T. J., Stetson, B., Stevens, V. M., Johnson, C. A., Penzien, D. B., \& Van Dorsten, B. (1991). The impact of cigarette smoking on headache activity in headache patients. Headache, 31, 329-332.

Pomerleau, O. F. (1986). Nicotine as a psychoactive drug: anxiety and pain reduction. Psychopharmacology Bulletin, 22, 865-869.

Pomerleau, O. F., Turk, D. C., \& Fertig, J. B. (1984). The effects of cigarette smoking on pain and anxiety. Addictive Behaviors, 9, 265-271.

Preacher, K. J., \& Hayes, A. F. (2004). SPSS and SAS procedures for estimating indirect effects in simple mediation models. Behav Res Methods Instrum Comput, 36, 717-731.

Rainville, P., Feine, J. S., Bushnell, M. C., \& Duncan, G. H. (1992). A psychophysical comparison of sensory and affective responses to four modalities of experimental pain. Somatosensory and Motor Research, 9, 265-277.

Rees, J. S., \& Addy, M. (2002). A cross-sectional study of dentine hypersensitivity. Journal of Clinical Periodontology, 29, 997-1003. 
Riley, J. L., 3rd, Robinson, M. E., Wise, E. A., Myers, C. D., \& Fillingim, R. B. (1998). Sex differences in the perception of noxious experimental stimuli: a metaanalysis. Pain, 74, 181-187.

Riley, J. L., 3rd, Tomar, S. L., \& Gilbert, G. H. (2004). Smoking and smokeless tobacco: increased risk for oral pain. Journal of Pain, 5, 218-225.

Rose, J. E., Ananda, S., \& Jarvik, M. E. (1983). Cigarette smoking during anxietyprovoking and monotonous tasks. Addictive Behaviors, 8, 353-359.

Rozen, T. D. (2005). Childhood exposure to second-hand tobacco smoke and the development of cluster headache. Headache, 45, 393-394.

Saag, K. G., Cerhan, J. R., Kolluri, S., Ohashi, K., Hunninghake, G. W., \& Schwartz, D. A. (1997). Cigarette smoking and rheumatoid arthritis severity. Annals of the Rheumatic Diseases, 56, 463-469.

Sahley, T. L., \& Berntson, G. G. (1979). Antinociceptive effects of central and systemic administrations of nicotine in the rat. Psychopharmacology, 65, 279-283.

Scott, S. C., Goldberg, M. S., Mayo, N. E., Stock, S. R., \& Poitras, B. (1999). The association between cigarette smoking and back pain in adults. Spine, 24, 10901098.

Shiffman, S., \& Jarvik, M. E. (1984). Cigarette smoking, physiological arousal, and emotional response: Nesbitt's paradox re-examined. Addictive Behaviors, 9, 9598.

Silverstein, B. (1982). Cigarette smoking, nicotine addiction, and relaxation. Journal of Personality and Social Psychology, 42, 946-950.

Sobel, M. E. (1982). Asymptotic confidence intervals for indirect effects in structural equation models. In S. Leinhart (Ed.), Sociological methodology 1982 (pp. 290312). San Francisco: Jossey-Bass. 
Stone, A. A., \& Shiffman, S. (1994). Ecological Momentary Assessment (EMA) in behavioral medicine. Annals of Behavioral Medicine, 16, 199-202.

Sullivan, M. J., Bishop, S. R., \& Pivik, J. (1995). The Pain Catastrophizing Scale: Development and validation. Psychological Assessment, 7, 524-532.

Sult, S. C., \& Moss, R. A. (1986). The effects of cigarette smoking on the perception of electrical stimulation and cold pressor pain. Addictive Behaviors, 11, 447-451.

Torelli, P., Cologno, D., \& Manzoni, G. C. (1999). Episodic and chronic cluster headache males: differences in age at onset and habits. In J. Olesen \& P. J. Goadsby (Eds.), Cluster Headache and related conditions (pp. 42-47). Oxford, England: Oxford University Press.

Tuomi, T., Heliovaara, M., Palosuo, T., \& Aho, K. (1990). Smoking, lung function, and rheumatoid factors. Annals of the Rheumatic Diseases, 49, 753-756.

Turner, J., Page-Shafer, K., Chin, D. P., Osmond, D., Mossar, M., Markstein, L., et al. (2001). Adverse impact of cigarette smoking on dimensions of health-related quality of life in persons with HIV infection. Aids Patient Care and STDS, 15, 615624.

Unell, L., Soderfeldt, B., Halling, A., \& Birkhed, D. (1999). Explanatory models for clinically determined and symptom-reported caries indicators in an adult population. Acta Odontologica Scandinavica, 57, 132-138.

Unrod, M., Kassel, J. D., \& Robinson, M. (2004). Effects of smoking, distraction, and gender on pain perception. Behavioral Medicine, 30, 133-139.

USDHHS. (2004). The Health Consequences of Smoking: A Report of the Surgeon General: U.S. Department of Health and Human Services, Centers for Disease Control and Prevention, National Center for Chronic Disease Prevention and Health Promotion, Office on Smoking and Health. 
Waller, D., Schalling, D., Levander, S., \& Edman, G. (1983). Smoking, pain tolerance, and physiological activation. Psychopharmacology, 79, 193-198.

Watson, D., Clark, L. A., \& Tellegen, A. (1988). Development and validation of brief measures of positive and negative affect: the PANAS scales. Journal of Personality and Social Psychology, 54, 1063-1070.

Wertz, J. M., \& Sayette, M. A. (2001). A review of the effects of perceived drug use opportunity of self-reported urge. Experimental and Clinical Psychopharmacology, 9, 3-13.

Winn, D. M. (2001). Tobacco use and oral disease. Journal of Dental Education, 65, 306-312.

Wolfe, F., \& Hawley, D. J. (1998). Psychosocial factors and the fibromyalgia syndrome. Zeitschrift fur Rheumatologie, 57 Suppl 2, 88-91.

Woodside, J. R. (2000). Female smokers have increased postoperative narcotic requirements. Journal of Addictive Diseases, 19, 1-10.

Yunus, M. B., Arslan, S., \& Aldag, J. C. (2002). Relationship between fibromyalgia features and smoking. Scandinavian Journal of Rheumatology, 31, 301-305. 
Appendices 
Appendix A: Smoking Status Questionnaire

1. Date of Birth:

Month Day Year

2. Sex: (check one) $\square$ Male $\square$ Female

3. Do you smoke cigarettes everyday? $\square$ Yes $\square$ No If No, stop here; If Yes, please continue

4. How many years have you been smoking daily?

5. How many cigarettes do you smoke per day on average?

6. Do you inhale? (circle one) NEVER SOMETIMES ALWAYS

7. Do you smoke more during the first two hours of the day than during the rest of the day? $\square$ Yes $\square$ No

8. How soon after you wake up do you smoke your first cigarette?

$\square$ Within 5 minutes

$\square$ 6-30 minutes

$\square$ 31-60 minutes

$\square$ After 60 minutes

9. Which of all the cigarettes you smoke would you most hate to give up?

$\square$ The first one in the morning

$\square$ The one with breakfast

$\square$ The one with lunch

$\square$ The one with dinner

$\square$ The last cigarette before going to bed

$\square$ Other:

10. Do you find it difficult to refrain from smoking in places where it is forbidden (eg. in church, at the library)? $\square$ Yes $\square$ No

11. Do you smoke if you are so ill that you are in bed most of the day?
$\square$ Yes
$\square$ No 


\section{Appendix B: Questionnaire of Smoking Urges-Brief}

Indicate how much you agree or disagree with each of the following statements by marking one of the circles between STRONGLY DISAGREE and STRONGLY AGREE. The closer you place your mark to one end or the other indicates the strength of your agreement or disagreement. We are interested in how you are thinking and feeling right now as you are filling out the

questionnaire.

1. I have a desire for a cigarette right now.
STRONGLY
DISAGREE
0
$0 \quad 0$
$\mathrm{O}$
O STRONGLY

2. Nothing would be better than smoking a cigarette right now.

STRONGLY

DISAGREE

$\mathrm{O}$

O

0

O

$\mathrm{O}$

0

STRONGLY
AGREE

3. If it were possible, I probably would smoke now.

\section{STRONGLY}

DISAGREE

\section{0}

O

O

O

0

0

STRONGLY
AGREE

4. I could control things better right now if I could smoke.

STRONGLY

DISAGREE

5. All I want right now is a cigarette.

STRONGLY DISAGREE

$\mathrm{O}$

$\mathrm{O}$

O

O

0

O STRONGLY

6. I have an urge for a cigarette.

\section{STRONGLY}

DISAGREE

\section{O}

O

0

7. A cigarette would taste good right now.

\section{STRONGLY}

DISAGREE

o

O

$\mathrm{O}$

O

O

O

STRONGLY
AGREE

8. I would do almost anything for a cigarette now.

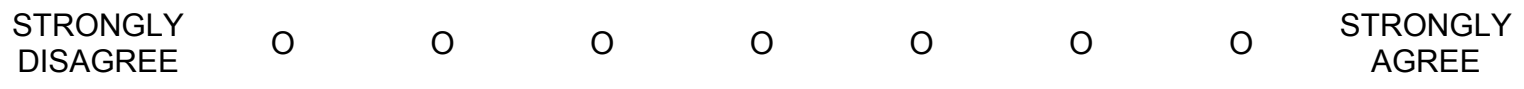

9. Smoking would make me less depressed.

STRONGLY DISAGREE

$0 \quad 0$

10. I am going to smoke as soon as possible.

STRONGLY

DISAGREE

0

$\mathrm{O}$

0

$\mathrm{O}$

O

STRONGLY
AGREE 


\section{Appendix C: Visual Analogue Scale (VAS)}

Instructions: Please place an up-and-down line ("|") on the scale where you feel it best represents how you feel right now, at this very moment.

How strong is your urge to smoke a cigarette is AT THIS EXACT MOMENT?

No Urge

At All
Strongest

Urge Ever 


\section{Appendix D: Smoking Consequences Questionnaire - Adult}

Instructions: This questionnaire is designed to assess beliefs people have about the consequences of smoking a cigarette. Below is a list of statements about smoking. We would like you to rate how LIKELY or UNLIKELY you believe each consequence is for you when you smoke. If the consequence seems UNLIKELY to you, circle a number from 0-4. If the consequence seems LIKELY to you, circle a number from 5-9. That is if you believe the consequence would never happen, circle 0; if you believe a consequence would happen every time you smoke, circle 9 . Use the guide below to aid you further. For example, if a consequence seems completely likely to you, you would circle 9 . If it seems a little unlikely to you, you would circle 4 .

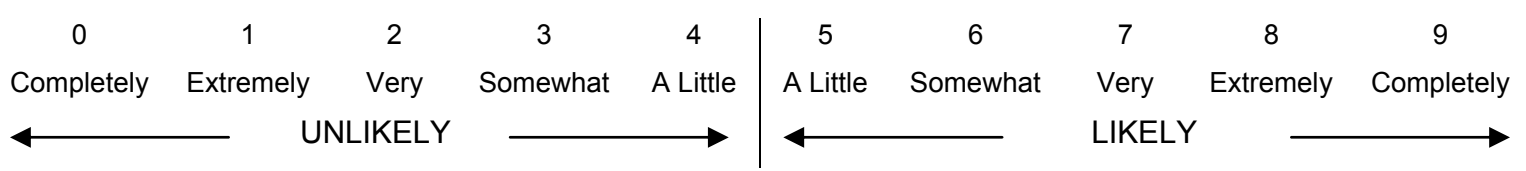

1. Cigarettes help me deal with anxiety or worry.

2. Smoking would ease my pain if I were hurting.

3. Nicotine "fits" can be controlled by smoking.

4. When I'm angry, a cigarette can calm me down.

5. I become more addicted the more I smoke.

6. If I were to experience pain, a cigarette would help reduce it.

7. If I'm tense, a cigarette helps me to relax.

8. Smoking a cigarette energizes me.

9. Cigarettes help me deal with anger.

10. If I hurt myself, I would feel less pain if I could smoke.

11. Smoking calms me down when I feel nervous.

12. I feel like I do a better job when I am smoking.

13. A cigarette can give me energy when I'm bored and tired.

14. Cigarettes can really make me feel good.

15. When I'm feeling happy, smoking helps keep that feeling.

16. When I feel pain, a cigarette can really help.

17. Smoking will satisfy my nicotine cravings.

18. Cigarettes help me reduce or handle tension.

19. I feel better physically after having a cigarette.

20. A cigarette can satisfy my urge to smoke.

21. If I hurt myself, I could cope with the pain without smoking.

22. If I'm feeling irritable, a smoke will help me relax.

23. I will become more dependent on nicotine if I continue smoking.

24. When I am upset with someone, a cigarette helps me cope.

25. I feel like smoking would help me cope with pain.

26. I like the way a cigarette makes me feel physically.

27. When I am worrying about something, a cigarette is helpful.

28. Smoking temporarily reduces those repeated urges for cigarettes.

$\begin{array}{llllllllll}0 & 1 & 2 & 3 & 4 & 5 & 6 & 7 & 8 & 9 \\ 0 & 1 & 2 & 3 & 4 & 5 & 6 & 7 & 8 & 9 \\ 0 & 1 & 2 & 3 & 4 & 5 & 6 & 7 & 8 & 9 \\ 0 & 1 & 2 & 3 & 4 & 5 & 6 & 7 & 8 & 9 \\ 0 & 1 & 2 & 3 & 4 & 5 & 6 & 7 & 8 & 9 \\ 0 & 1 & 2 & 3 & 4 & 5 & 6 & 7 & 8 & 9 \\ 0 & 1 & 2 & 3 & 4 & 5 & 6 & 7 & 8 & 9 \\ 0 & 1 & 2 & 3 & 4 & 5 & 6 & 7 & 8 & 9 \\ 0 & 1 & 2 & 3 & 4 & 5 & 6 & 7 & 8 & 9 \\ 0 & 1 & 2 & 3 & 4 & 5 & 6 & 7 & 8 & 9 \\ 0 & 1 & 2 & 3 & 4 & 5 & 6 & 7 & 8 & 9 \\ 0 & 1 & 2 & 3 & 4 & 5 & 6 & 7 & 8 & 9 \\ 0 & 1 & 2 & 3 & 4 & 5 & 6 & 7 & 8 & 9 \\ 0 & 1 & 2 & 3 & 4 & 5 & 6 & 7 & 8 & 9 \\ 0 & 1 & 2 & 3 & 4 & 5 & 6 & 7 & 8 & 9 \\ 0 & 1 & 2 & 3 & 4 & 5 & 6 & 7 & 8 & 9 \\ 0 & 1 & 2 & 3 & 4 & 5 & 6 & 7 & 8 & 9 \\ 0 & 1 & 2 & 3 & 4 & 5 & 6 & 7 & 8 & 9 \\ 0 & 1 & 2 & 3 & 4 & 5 & 6 & 7 & 8 & 9 \\ 0 & 1 & 2 & 3 & 4 & 5 & 6 & 7 & 8 & 9 \\ 0 & 1 & 2 & 3 & 4 & 5 & 6 & 7 & 8 & 9 \\ 0 & 1 & 2 & 3 & 4 & 5 & 6 & 7 & 8 & 9 \\ 0 & 1 & 2 & 3 & 4 & 5 & 6 & 7 & 8 & 9 \\ 0 & 1 & 2 & 3 & 4 & 5 & 6 & 7 & 8 & 9 \\ 0 & 1 & 2 & 3 & 4 & 5 & 6 & 7 & 8 & 9 \\ 0 & 1 & 2 & 3 & 4 & 5 & 6 & 7 & 8 & 9 \\ 0 & 1 & 2 & 3 & 4 & 5 & 6 & 7 & 8 & 9 \\ 0 & 1 & 2 & 3 & 4 & 5 & 6 & 7 & 8 & 9\end{array}$


This scale consists of a number of words that describe different feelings and emotions. Read each item and then mark the appropriate answer in the space next to that word. Indicate to what extent you felt this way during the past week. Use the following scale to record your answers.

$\begin{array}{cc}\begin{array}{c}1 \\ \text { very slightly } \\ \text { or not at all }\end{array} & \begin{array}{c}2 \\ \text { a little }\end{array} \\ & \text { interested } \\ & \text { distressed } \\ & \text { excited } \\ & \text { upset } \\ \text { strong } & \text { guilty } \\ \text { scared } & \text { hostile } \\ \text { proud } & \text { enthusiastic }\end{array}$

3

moderately

4

quite a bit

5

extremely 


\section{Appendix F: PANAS-I}

This scale consists of a number of words that describe different feelings and emotions. Read each item and then mark the appropriate answer in the space next to that word. Indicate to what extent you feel this way at this moment. Use the following scale to record your answers.

3 moderately

4 quite a bit 5 extremely

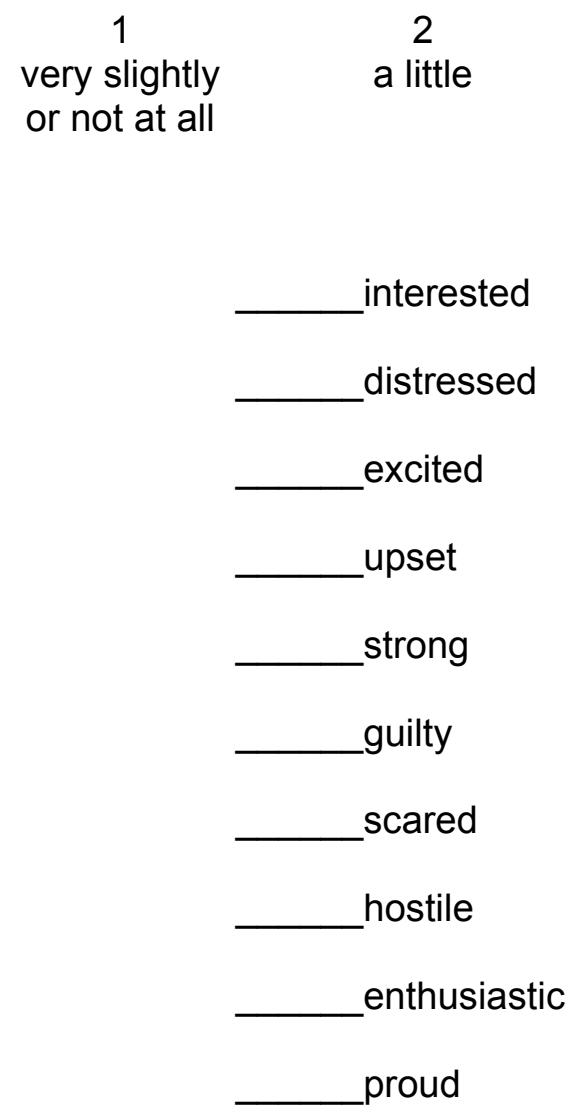

very slightly

interested

irritable

alert

ashamed

inspired

nervous

determined

attentive

jittery

active

afraid 


\section{Appendix G: Pain Catastrophizing Scale}

Everyone experiences painful situations at some point in their lives. Such experiences may include headaches, tooth pain, joint or muscle pain. People are often exposed to situations that may cause pain such as illness, injury, dental procedures or surgery.

We are interested in the types of thoughts and feelings that you have when you are in pain. Listed below are thirteen statements describing different thoughts and feelings that may be associated with pain. Using the following scale, please indicate the degree to which you have these thoughts and feelings when you are experiencing pain.

$\begin{array}{ccccc}\mathbf{0} & \mathbf{1} & \mathbf{2} & \mathbf{3} & \mathbf{4} \\ \text { not at all } & \begin{array}{c}\text { to a slight } \\ \text { degree }\end{array} & \begin{array}{c}\text { to a moderate } \\ \text { degree }\end{array} & \begin{array}{c}\text { to a great } \\ \text { degree }\end{array} & \text { all the time }\end{array}$

\section{When I'm in pain ...}

1. I worry all the time about whether the pain will end.

2. I feel I can't go on.

3. It's terrible and I think it's never going to get any better.

4. It's awful and I feel that it overwhelms me.

5. I feel I can't stand it anymore.

6. I become afraid that the pain will get worse.

7. I I keep thinking of other painful events.

8. I anxiously want the pain to go away.

9. I can't seem to keep it out of my mind.

10. I keep thinking about how much it hurts.

11. I keep thinking about how badly I want the pain to stop.

12. There's nothing I can do to reduce the intensity of the pain.

13. I wonder whether something serious may happen. 
Appendix H: NRS Measure of Pain Intensity

Please put a circle around the number that best describes your pain, at its worst, since placing your hand in the water.

*Note: 0 means 'No pain' and 10 means 'Pain as bad as you can imagine'

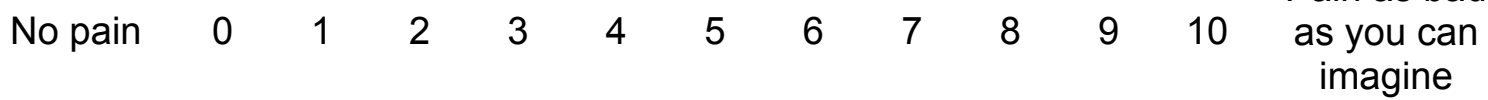

